Thorax (1952), 7, 188.

\title{
A TABLE FOR PULMONARY RESECTION IN THE PRONE POSITION
}

\author{
BY \\ HANS RAHBEK S $\phi$ RENSEN \\ From the Department of Thoracic Surgery, University Hospital, Copenhagen
}

(RECEIVED FOR PUBLICATION NOVEMBER 23, 1951)

One of the problems connected with pulmonary resection is how to avoid gravity drainage of secretions from diseased to healthy parts of the lung. One method is to employ one of the tubes by which a separate ventilation of the different parts of the lung may be maintained, and another is to place the patient face down. The latter method has the advantage of not entailing narrowing of the lumina of the respiratory tract, so that the resistance is the same as in ordinary tracheal intubation.

For the prone positioning the surgeon has the choice of employing one of the special, rather expensive tables, or of supporting the patient with sand-bags and cushions, a cumbersome and not quite stable method.

At the department of thoracic surgery of the University Hospital in Copenhagen we have from January, 1951, been using a table of our own design which has proved satisfactory for surgeons as well as for anaesthetists. Since it is cheap and of simple construction it will be described and illustrated in a working drawing.

Fig. 1.-Working drawing.

FIG. 2. -The patient is shown in the operating position for left-sided thoracotomy.

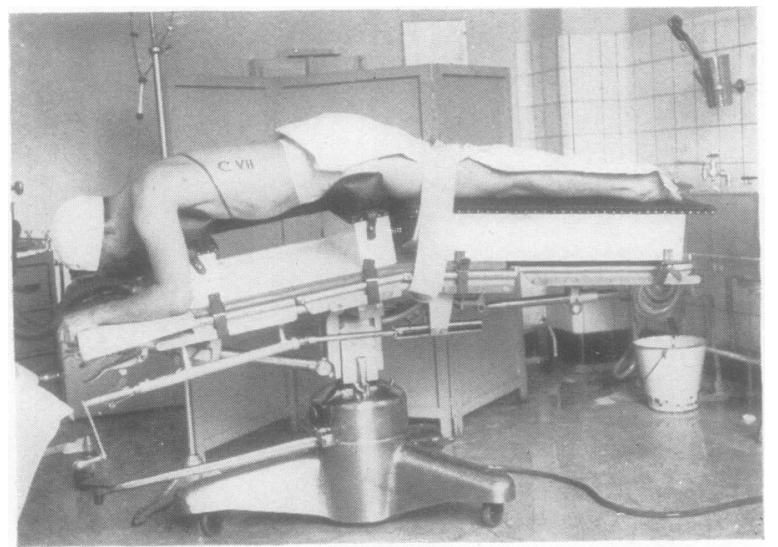

Fic. 2.
The unit is made up of three detached parts (Fig. ) which may be strapped to any standard operating tabe. $\mathrm{A}$ is a plate to support the arms and an adjustable headrest $a$. B is a box, $15 \mathrm{~cm}$. high, $45 \mathrm{~cm}$. broad, a $45 \mathrm{~cm}$. long, to support the trunk. One side of the box is fitted with a carriage $b_{\mathrm{I}}$. When removed, the latter leaves a gap $30 \mathrm{~cm}$. long and $22.5 \mathrm{~cm}$. deep. TwO horsehair pillows with plastic artificial leather covers also belong to this part of the table. $\mathrm{C}$ is a box $\mathrm{Co}_{0}$ support the lower limbs.

The table is made of deal, with plywood for the botto of the boxes. The upper surfaces of $B$ and $C$ gre padded and covered with plastic artificial leather. The head-rest, $a$, is also padded.
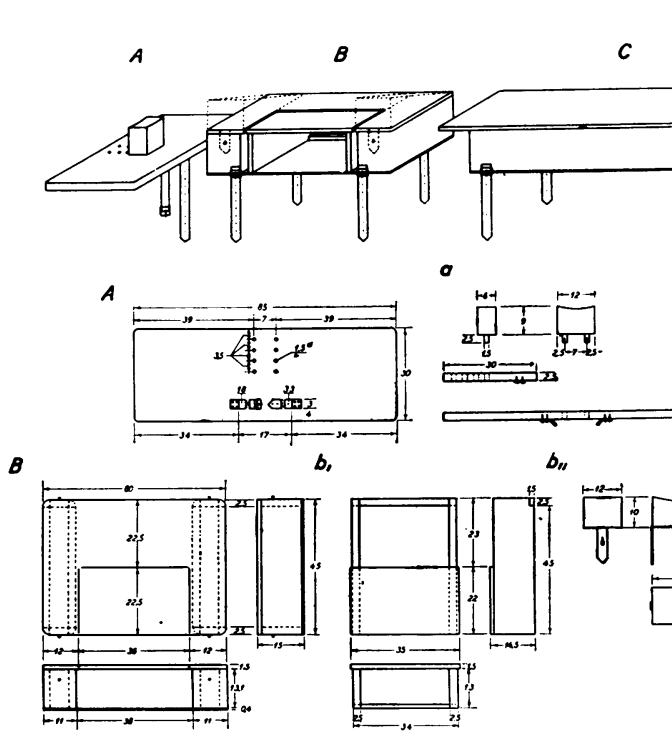

"
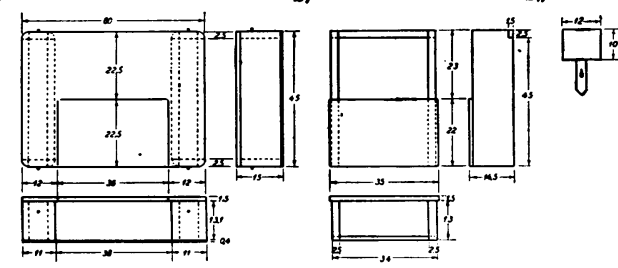

$\boldsymbol{c}$

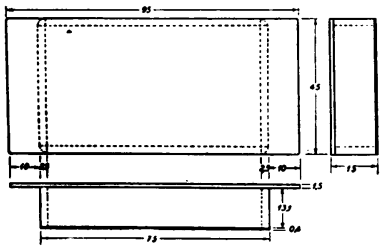

Fig. 1. 
The three parts of the unit are strapped to a standard operating table, B with the gap to the right or left according to which side is involved. Anaesthesia is begun while the patient is supine. After tracheal intubation he is turned face down, his forehead supported on the head-rest. One of the pillows $\left(b_{\mathrm{II}}\right)$ is tucked from the affected side (cephalic to the gap) to support the upper part of the chest, and the other pillow is placed immediately above the symphysis pubis. The pillows may be buttoned on the table. When the carriage is removed, the anterior surface of the affected side is accessible. The operating table is adjusted so that each of the boxes $\mathrm{B}$ and $\mathrm{C}$ forms an angle of $15^{\circ}$ with the horizontal plane, and, moreover, it is tilted to make the upper surface of the pillows horizontal. The positioning is completed (Fig. 2) after a thin pillow has been placed under the legs (not shown on the figure) to prevent hyperextension of the knees.

The unit allows free access to the operating field. It is easy to perform manually assisted or controlled respiration (frequently even easier than in the lateral position), even though the healthy side does rest lightly on the table. In our opinion this is an advantage, since it prevents too much over-stretching of the lumbar column in the often elderly patients.

There has been no case of pressure paralysis, permanent or temporary, but on two occasions we have observed cyanosis and congestion of the lower limbs due to pressure from the lower pillow which is apt to lie immediately below the femoral vessels, if the subject is short. This congestion did not cause any embarrassment, but it must be realized that a wrong positioning of this pillow may involve the risk of complications. 